METALLURGY AND FOUNDRY ENGINEERING - Vol. 35, 2009, No. 2

Bogdan Pawłowski*, Piotr Bała*, Janusz Krawczyk*

\title{
SOME FACTORS INFLUENCING THE DETERMINATION OF EUTECTOID TRANSFORMATION START AND FINISH TEMPERATURES IN HYPOEUTECTOID STEELS
}

\section{INTRODUCTION}

Neither the Polish Standard PN EN 10052:1993 nor the standards of other European Union countries (e.g. British BS EN BS EN 10052:1994) define eutectoid transformation start (during cooling) and finish (during heating) temperatures in steels. Thus, there is a lack of standard validations of the temperature determining the start of the coexistence range of ferrite and austenite during heating as well as the temperature determining the finish of this range, during cooling, in hypoeutectoid steels. Knowledge of such temperature range in the steel structure is very important e.g. during a heat-mechanical treatment of DP steel (dual phase) $[1 \div 3]$. Problems of lacking the proper definitions of phase transformation temperatures in steels was broadly discussed in paper [4].

Phase transformation temperatures in steels (the so-called critical temperatures) are the most often estimated by the dilatometric method where the dilatograms of heating samples - with the given, not high rate (usually app. $0.05^{\circ} \mathrm{C} / \mathrm{sec}$.) - are recorded. It was shown in paper [5] that the possibility of determination of the finish temperature of the pearlite into austenite transformation, during heating, can depend on the interlamellar spacing in pearlite. The heating dilatograms together with the interlamellar spacing in pearlite of steel containing $0.1 \% \mathrm{C}$ and $0.5 \% \mathrm{Mn}$ are shown in Figure 1 [5]. Samples from the same steel but of various pearlite morphologies were obtained by an application of different kinds of the heat treatment: hot-rolled and air cooled to room temperature, semi hot-rolled, hot-rolled and reheated to $1000^{\circ} \mathrm{C}$ then cooled at different cooling rates [5].

* Ph.D.: Faculty of Metals Engineering and Industrial Computer Science, AGH - University of Science and Technology, Kraków, Poland; e-mail: bpawlow@agh.edu.pl 
a)

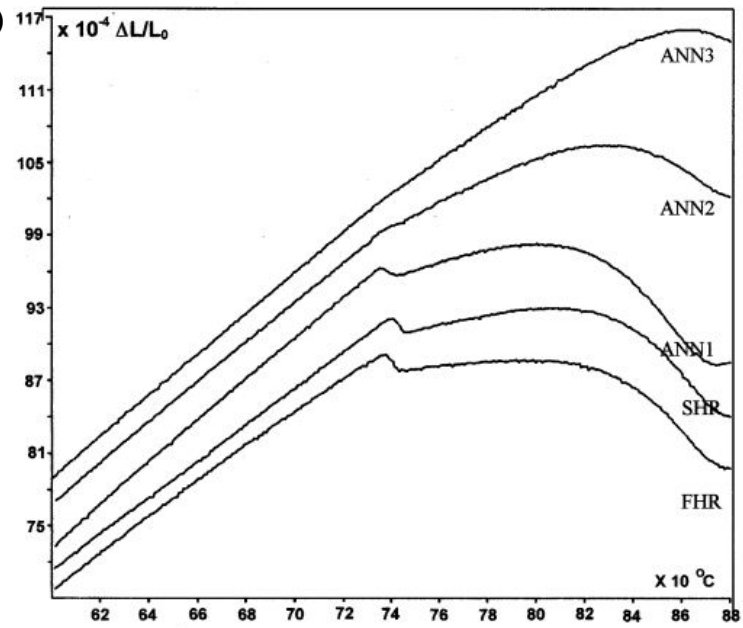

b)

\begin{tabular}{|l|c|}
\hline Specimen & Interlamellar spacing $(\mu \mathrm{m})$ \\
\hline FHR & $0.14 \pm 0.01$ \\
SHR & $0.17 \pm 0.04$ \\
ANN1 & $0.18 \pm 0.03$ \\
ANN2 & $0.25 \pm 0.05$ \\
ANN3 & $0.29 \pm 0.06$ \\
\hline
\end{tabular}

Fig. 1. Heating dilatograms (a), Interlamellar spacing in pearlite (b). Interlamellar spacing in steel $0.1 \% \mathrm{C}, 0.5 \% \mathrm{Mn}[5]$

Dilatometric examinations (performed by means of the Adamel Lhomargy DT1000 dilatometer) indicate that the smaller interlamellar spacing in pearlite the more distinct dilatation effect - from the finish of the eutectoid transformation, in the heating dilatograms. In the case of large interlamellar spaces in pearlite the dilatation effect corresponding to the end of the eutectoid transformation is practically invisible (Fig. 1. Samples ANN2 and ANN3). Differences in the initial structure of the examined dilatometric samples revealed themselves also in temperature values at the beginning of the pearlite into austenite transformation. Those differences are seen in Figure 1 of paper [5], however the authors did not specify them.

Examples of the heating dilatograms together with the differential curves and the estimated transformation temperatures for two hypoeutectoid steels are presented in this paper. Examinations were performed by means of two dilatometers of different resolutions.

\section{MATERIAL AND THE INVESTIGATION METHOD}

Examinations were performed for two hypoeutectoid C35 and C56 steels, which chemical compositions are given in Table 1. Before the dilatometric examinations the material 
was normalised by annealing: $\mathrm{C} 35$ steel in $860^{\circ} \mathrm{C}$ for 30 minutes, while $\mathrm{C} 56$ steel in $830^{\circ} \mathrm{C}$ also for 30 minutes, then air cooled. Microstructures of the investigated steels, after the normalizing annealing, are shown in Figure 2.

Table 1. Chemical composition of the investigated steels

\begin{tabular}{|c|c|c|c|c|c|c|c|c||}
\hline \multirow{2}{*}{ Steel } & \multicolumn{8}{|c|}{ Chemical composition, weight percent } \\
\cline { 2 - 10 } & $\mathrm{C}$ & $\mathrm{Mn}$ & $\mathrm{Si}$ & $\mathrm{P}$ & $\mathrm{S}$ & $\mathrm{Cr}$ & $\mathrm{Ni}$ & $\mathrm{Cu}$ \\
\hline $\mathrm{C} 35$ & 0.38 & 0.66 & 0.25 & 0.013 & 0.002 & 0.05 & 0.07 & 0.15 \\
\hline $\mathrm{C} 56$ & 0.55 & 0.61 & 0.20 & 0.019 & 0.015 & 0.04 & 0.02 & 0.03 \\
\hline
\end{tabular}

a)

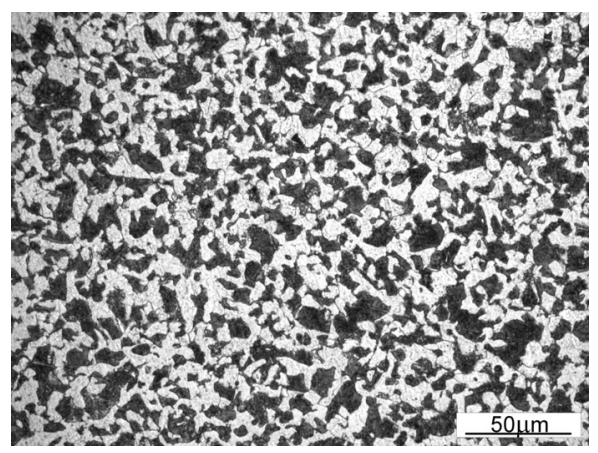

c)

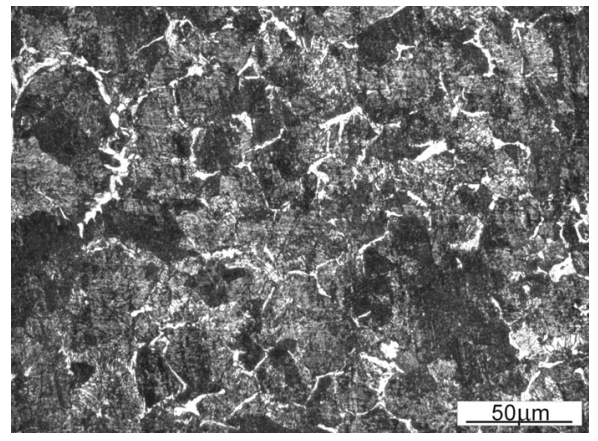

b)

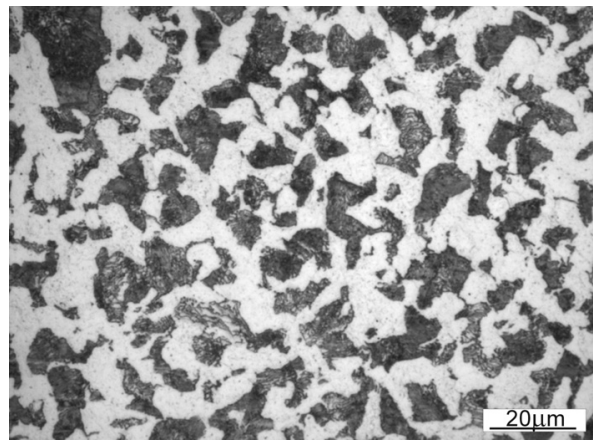

d)

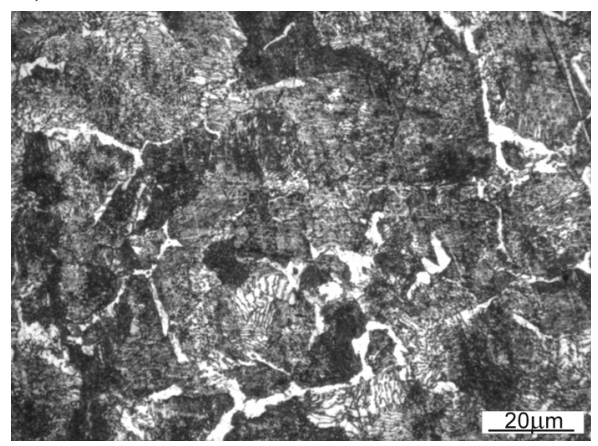

Fig. 2. Microstructure of the investigated steels after the normalizing annealing: (a, b) C35 steel, (c, d) C56 steel. Etched in 2\% Nital

Dilatometric examinations at the heating rate of $0.05^{\circ} \mathrm{C} / \mathrm{sec}$., in a vacuum of $10^{-2} \mathrm{mbar}$, for samples of dimensions $\varnothing 2 \times 12 \mathrm{~mm}$ were performed by the Adamel-Lhomargy DT1000 dilatometer. The heating dilatograms for two investigated steels together with the differential curves are presented in Figures 3 and 4. 


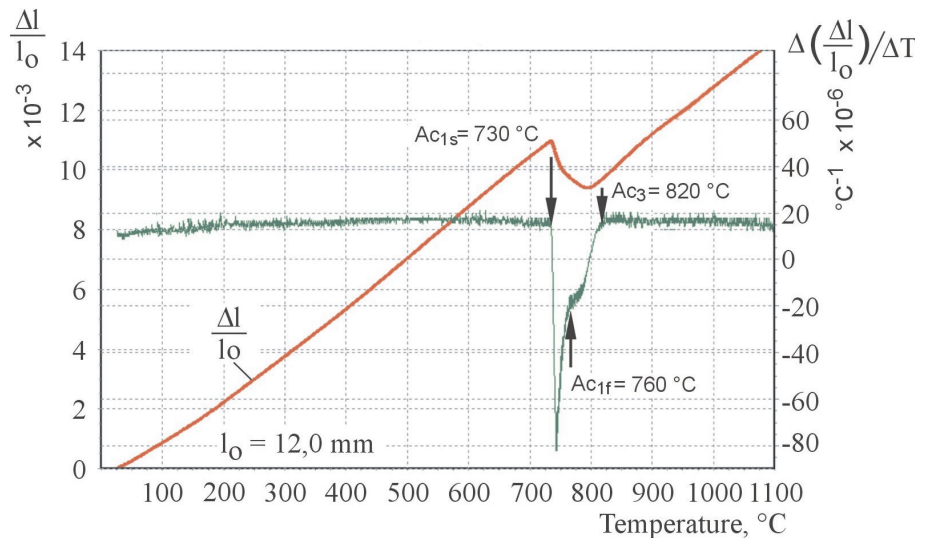

Fig. 3. Heating dilatogram of C35 hypoeutectoid steel with the differential curve. Sample after the normalizing annealing. DT1000 dilatometer
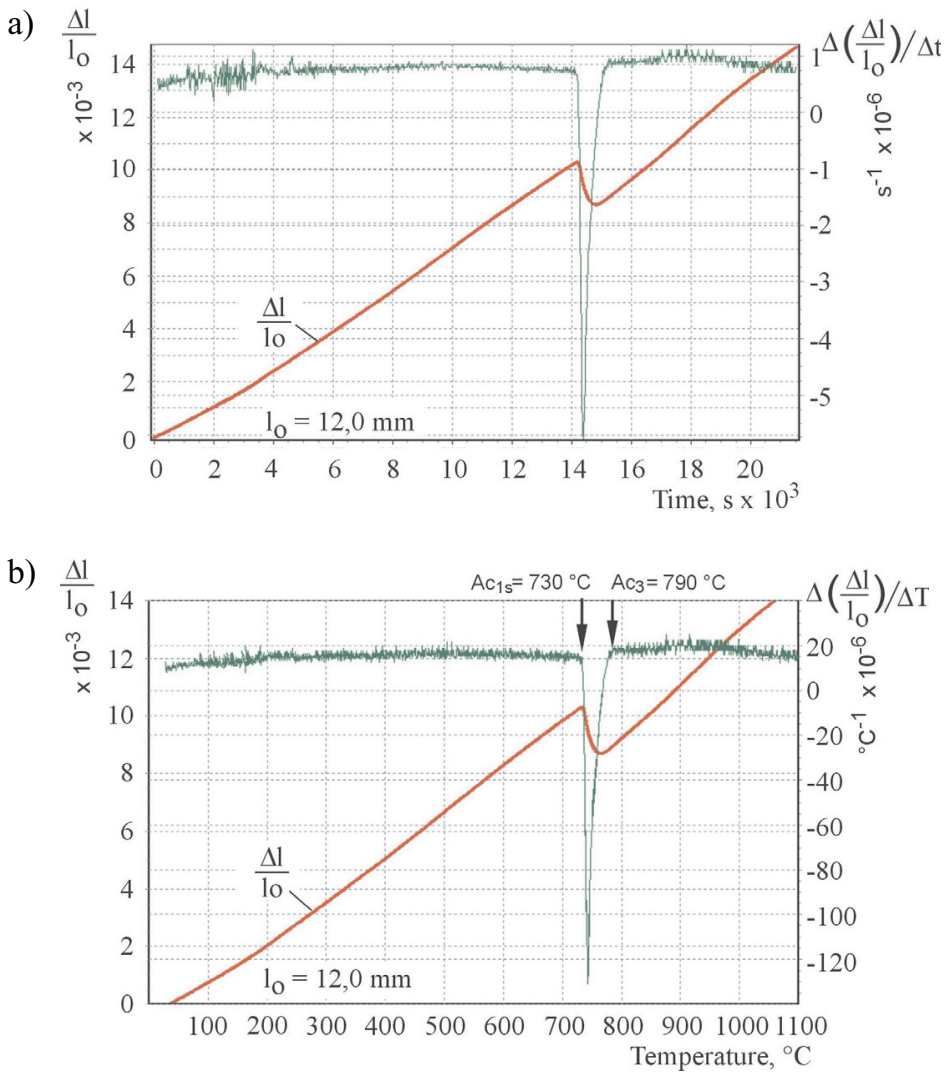

Fig. 4. Heating dilatogram for C56 hypoeutectoid steel sample: (a) in the elongation-temperature system, (b) in the elongation-time system with the differential curve diagram. Sample after the normalizing annealing. DT1000 dilatometer 
Since none dilatation effects corresponding to the finish of the eutectoid transformation were seen in the heating dilatogram of $\mathrm{C} 56$ steel, the additional examinations were performed on the identically prepared sample of this steel (normalizing annealing: $830^{\circ} \mathrm{C} /$ 30 min, air cooling) by means of the high-resolution L78 RITA dilatometer (thanks to the courtesy of the Linseis Application Laboratory, Germany). The obtained results, in the form of the heating dilatograms in the systems: elongation-temperature and elongation-time together with the differential curve diagram are presented in Figure 5.

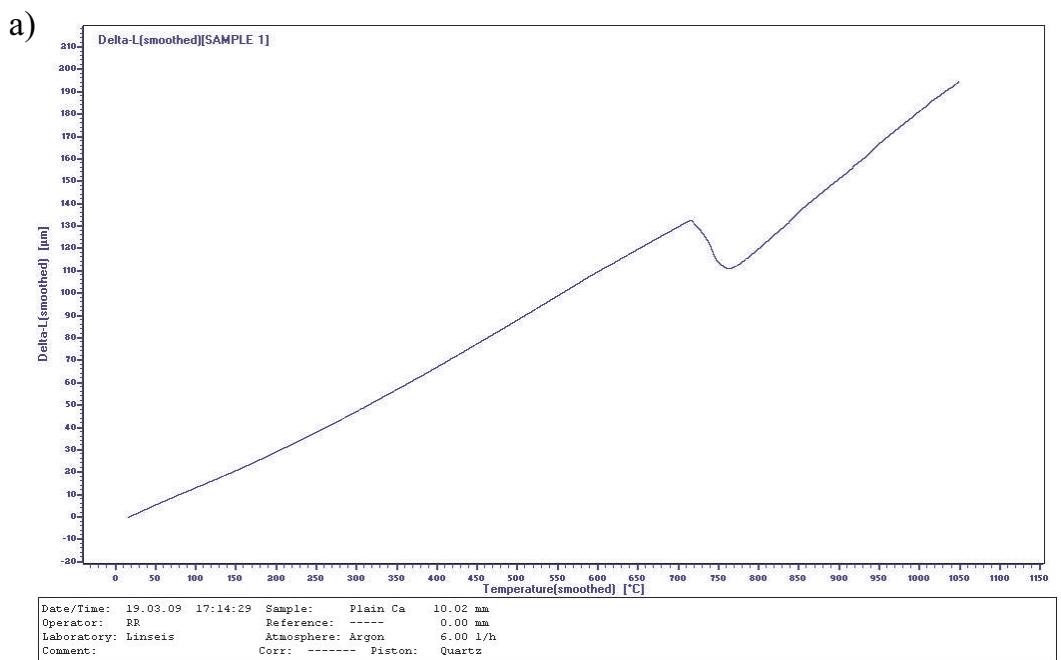

b)

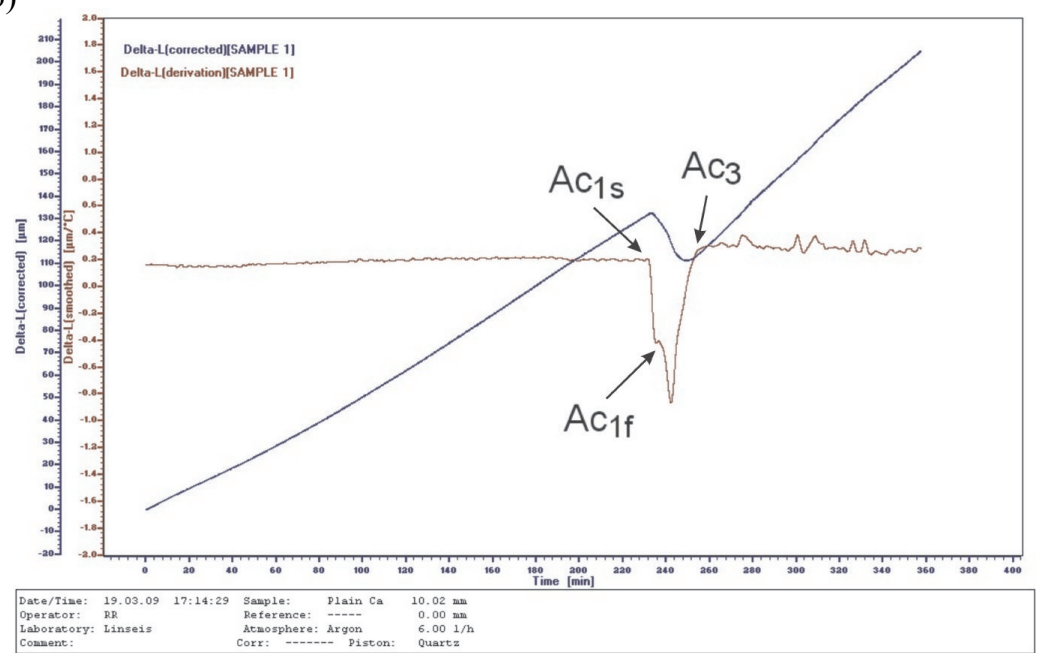

Fig. 5. Heating dilatogram for C56 hypoeutectoid steel sample: (a) in the elongation-temperature system, (b) in the elongation-time system together with the differential curve diagram. Sample after the normalizing annealing. L78 RITA dilatometer 


\section{THE OBTAINED RESULTS AND THEIR DISCUSSION}

Dilatometric examinations of C35 steel performed by means of the DT1000 dilatometer revealed distinct dilatometric effects corresponding to the start and finish of the pearlite transformation into austenite - at temperatures marked as $\mathrm{Ac}_{1 \mathrm{~s}}$ and $\mathrm{Ac}_{1 \mathrm{f}}$ respectively, as well as to the end of the ferrite transformation into austenite $\left(\mathrm{Ac}_{3}\right.$ temperature). The temperature values of individual transformations were readout from the differential curve (the relevant places together with the corresponding transformation temperatures are marked on this curve in Fig. 3). In the case of C56 steel the determination of the occurrence place of the dilatation effect related to the pearlitic transformation finish is not possible neither on the dilatometric curve (DT1000 dilatometer) nor on the differential curve. Only the temperature of the pearlitic transformation start $\left(\mathrm{Ac}_{1 \mathrm{~s}}\right.$ temperature) and the temperature of the end of the ferrite into austenite transformation ( $\mathrm{Ac}_{3}$ temperature) can be determined from the differential curve. According to the previously cited paper [5] the lack of the dilatation effect related to the finish of the pearlitic transformation - on the heating dilatogram, can be linked to a larger interlamellar spacing in this steel pearlite as compared with C35 steel. Dilatometric samples of both steels were exposed to the normalizing annealing. Since the structure after such annealing constitutes the initial structure for various processes of heat or mechanical-heat treatments the possibility of the determination of phase transformation temperatures for samples after annealing is essential.

The change of the pearlite morphology (decreasing of interlamellar spacing) by means of the relevant heat treatment, as presented in reference [5], would probably allow to determine the temperature of the pearlitic transformation finish for C56 steel (using DT 1000 dilatometer). However, an application of a heat treatment different, than normalizing annealing, would change the initial structure of this steel for further treatments, thus, making the obtained temperature $\mathrm{Ac}_{1 \mathrm{f}}$ quite useless. Due to this, the additional dilatometric examinations during heating were performed - by means of the L78 RITA high-resolution dilatometer, for C56 steel samples after the normalizing annealing. The heating rate was identical as for examinations made by the DT1000 dilatometer (equal $0.05^{\circ} \mathrm{C} / \mathrm{s}$ ). Examinations were performed in the protective argon atmosphere. Temperatures of the start $\left(\mathrm{Ac}_{1 \mathrm{~s}}\right)$ and finish $\left(\mathrm{Ac}_{1 \mathrm{f}}\right)$ of the pearlitic transformation as well as a temperature of the end of the ferrite into austenite transformation $\left(\mathrm{Ac}_{3}\right)$ can be estimated from the obtained dilatograms and from the differential curve. The L78 RITA dilatometer is characterised by a much better resolution than the DT1000 dilatometer and this enables the determination of a temperature of the pearlitic transformation finish, $\mathrm{Ac}_{1 \mathrm{f}}$, for samples exposed previously to normalizing annealing, which means for the proper initial structure for eventual further procedures of heat treatments. The differential curves - obtained by measurements made by both dilatometers, in the temperature range from the beginning of the pearlitic transformation $\left(\mathrm{Ac}_{1 \mathrm{~s}}\right)$ to the beginning of only austenite occurrence in the steel structure at heating $\left(\mathrm{Ac}_{3}\right)$ are of a characteristic V shape (Figs 3-6). It is rather puzzling, that in the case of C56 steel (con- 
taining very small amounts of ferrite) the effect related to the finish of the pearlitic transformation appears on the left slope of a V-shaped differential curve, while in the case of C35 steel, which has a majority of ferrite in its initial structure, this effect appears on the right $\mathrm{V}$ slope of the differential curve fragment. Regardless of various fractions of pearlite and ferrite in the initial structure of both investigated steels and a different carbon content, the maximum shrinkage effect - in the range of the investigated phase transformations, related to the specific volume of ferrite, pearlite and austenite equals for both samples approximately $30 \mu \mathrm{m}$. From the dilatometric diagrams presented in paper [5] can be observed that immediately after the end of the pearlite into austenite transformation but before the end of the ferrite into austenite transformation an instantaneous volume increase of the sample occurs. Such a phenomenon does not occur in the hereby paper results, even for C35 steel with high ferrite content. Assuming that immediately after the pearlitic transformation finishes the transformation of ferrite into austenite starts (it means the transformation related to the decrease of the specific volume), this instantaneous increase of the volume is difficult to be explained. Presumably, this can be relevant to eventual processes of carbon diffusion from austenite (formed from pearlite) rich in carbon - into austenite (formed from ferrite) of a small carbon content.

\section{CONCLUSIONS}

The dilatometric examinations of two kinds of plain carbon hypoeutectoid steels indicated, that the determination of a temperature of the eutectoid transformation finish, during heating, is - in certain cases, impossible, due to the lack of the effect related to this stage on the dilatometric curve. It is obvious that applying the dilatometer of a higher resolution capacity can be in such cases intentional and justified. However, the dilatometric examinations performed within this study revealed serious doubts and raised certain questions related to the phase transformation mechanisms. Explanations of these doubts require further studies both dilatometric and microstructural in the discussed range of phase transformations.

\section{Acknowledgments}

The authors would like to express their gratitude to the Linseis Application Laboratory, Germany for the possibility of performing examinations by means of the high-resolution dilatometer L78 RITA.

\section{REFERENCES}

[1] Blicharski M.: Inżynieria materiałowa - stal, WNT, Warszawa, (2004)

[2] Hadasik E.: Badania plastyczności metali, Wyd. Politechniki Śląskiej, Gliwice, (2008) 
[3] Turczyn S., Dziedzic M.: Walcowanie blach karoseryjnych z nowej generacji stali, Hutnik - Wiadomości Hutnicze, 69 (2002) 4, 126-132

[4] Pawłowski B., Pacyna J.: Temperatury przemian fazowych w stalach, Hutnik - Wiadomości Hutnicze, (2010) (w druku)

[5] Garcia de Andrés C., Caballero F.G., Capdevila C.: Dilatometric characterization of pearlite dissolution in $0.1 \mathrm{C}-0.5 \mathrm{Mn}$ low carbon low manganese steel, Scripta Materialia, 38 (1998) 12, 1835-1842

Received

December 2009 